\title{
Diagram Kontrol Kadar Sitral dalam Minyak Sereh Dapur sebagai Jaminan Mutu Kestabilan Optimasi Alat GCMS
}

\author{
Yusuf Habibi* \\ Laboratorium Terpadu Universitas Islam Indonesia \\ Jl Kaliurang Km 14,5 Sleman Yogyakarta 55584 \\ *corresponding author : yusuf.habibi@uii.ac.id \\ DOI : 10.20885/ijca.vol3 .iss2.art6
}

\section{ARTIKEL INFO}

Diterima : 19 Juni 2020

Direvisi : 05 September 2020

Diterbitkan : 09 September 2020

Kata kunci : Minyak Sereh Dapur, GCMS, Diagram kontrol

\begin{abstract}
ABSTRAK
Telah dilakukan penelitian penentuan control chart kadar sitral dalam minyak sereh dapur sebagai jaminan mutu kestabilan optimasi alat Gas Chromatography Mass Spectrometry (GCMS). Metode GCMS merupakah salah satu metode yang cukup umum digunakan dalam analisis kandungan senyawa citral pada minyak sereh. Secara umum, minyak sereh dapur mempunyai 2 senyawa khas sitral, yaitu cis-sitral didapatkan pada waktu retensi 8,69 menit dan trans-sitral diperoleh pada waktu retensi 9,14 menit. Rata-rata kadar cis-sitral diperoleh $34,36 \%$ dan trans-sitral diperoleh 57,56\%. Masing-masing cis-sitral dan trans-sitral masuk dalam rentang atas dan rentang bawah control chart selama 8 minggu. Hal ini menunjukkan bahwa optimasi alat GCMS dalam kondisi stabil.
\end{abstract}

\section{ARTICLE INFO}

Received : 19 June 2020

Revised : O5 September 2020

Published :09 September 2020

Keywords : Lemongrass oil, GCMS, Control chart

\section{ABSTRACT}

Determination of control chart levels of citral in citronella oil as a guarantee of quality and stability of the Gas Chromatography Mass Spectrometry (GCMS) has been studied. The GCMS method is a commonly method used in the analysis of citral compounds in lemongrass oil. Generally, citronella oil has 2 typical citral compounds, namely cis-citral obtained at a retention time of 8.69 minutes and trans-citral obtained at a retention time of 9.14 minutes. The mean of cis-citral levels was $34.36 \%$ and trans-citral levels were $57.56 \%$. Cis-citral and trans-citral, respectively, entered the upper and lower ranges of the control chart for 8 weeks. These results show that the GCMS methods has stable condition for analysis of citral coumpunds.

\section{PENDAHULUAN}

Minyak atsiri merupakan minyak nabati yang sekarang sudah banyak dimanfaatkan baik dari pemanfaatan aroma minyak atsiri sampai pemanfaatan minyak atsiri sebagai obat-obatan dan zat aditif pada makanan. Minyak atsiri sekarang sudah dijadikan produk ekspor Indonesia meliputi minyak sereh, minyak pala, minyak nilam, minyak cengkeh dan minyak atsiri yang lain [1]. Minyak sereh selama ini yang dikenal ada dua macam yaitu minyak sereh wangi dan minyak sereh dapur. Minyak sereh dapur mudah didapatkan disekitar kita dan banyak di pasar serta murah dari sisi ekonomi. Oleh karena itu minyak sereh dapur lebih banyak digunakan daripada minyak serai wangi, meski kualitas minyak serai wangi lebih bagus, sehingga penulis menggunakan minyak serah dapur dalam penelitian ini [2]. Pengujian minyak atsiri sereh dapur untuk parameter senyawa khas Citral sesuai Standard Nasional Indonesia (SNI) dapat menggunakan GC-FID, kendala yang ada adalah standar Citral yang susah diperoleh dan mahal [3]. Maka dari itu penelitian pengujian minyak atsiri sereh dapur menggunakan alat GCMS, dimana dapat diperoleh senyawa khas Citral melalui fragmentasi Mass Spektra. 
Pengembangan metode dari SNI yang seharusnya menggunakan alat GC-FID menjadi GCMS, tentu memerlukan validasi dan verifikasi terlebih dahulu. Peneliti telah mendapatkan setting optimasi alat GCMS yang optimal untuk minyak atsiri dengan melihat kadar senyawa sesuai jaminan mutu SNI melalui penelitian "Pengaruh Variasi Optimasi Alat GCMS Terhadap Kadar 1,8-cineol pada Minyak Kayu Putih". Setting optimasi alat GCMS meliputi: suhu injektor dan detektor 200 C, suhu interface $300 \mathrm{C}$, suhu kolom 60 - $200 \mathrm{C}$ dengan kenaikan $10 \mathrm{C}$ /menit, tekanan $20 \mathrm{kPa}$, dan laju alir kolom 0,5 $\mathrm{ml} / \mathrm{mnt}$ [4]. Pada penelitian ini dilakukan optimasi alat GCMS terhadap berbagai minyak atsiri untuk mendapatkan nilai simpangan, dan hasil simpangan kecil menunjukkan optimasi alat GCMS dapat digunakan secara umum untuk minyak atsiri [5].

Penelitian sebelumnya menunjukkan bahwa optimasi alat GCMS yang dilakukan terhadap sampel minyak atsiri nilam, jahe dan cengkeh didapatkan nilai RDP dibawah $10 \%$ dengan hasil optimasi tersebut teliti [6]. Dari penelitian sebelumnya tersebut, maka jaminan mutu lain yang dapat dilakukan adalah dengan mengetahui kestabilan metoda optimasi atau control chart. Bagian penting dari control chart adalah garis tengah dan garis kontrol yang terdiri dari garis batas atas dan garis batas bawah [7]. Salah satu teknik yang umum digunakan dalam Statistical Proces Control SPC) adalah penggunaan diagram kontrol statistika untuk mengetahui apakah proses tersebut stabil atau tidak, baik mean maupun variabilitasnya [8].

\section{METODE PENELITIAN}

\subsection{Alat dan Bahan}

Alat yang digunakan dalam penelitian ini adalah GCMS Shimadzu QP2010SE, dengan kolom RTX$5 \mathrm{MS}$, panjang $30 \mathrm{~m}$, diameter $0,25 \mathrm{~mm}$ dan gas Helium sebagai gas carrier. Bahan yang digunakan adalah sampel minyak sereh dapur yang didapatkan di pasar tradisional.

\subsection{Penentuan Diagram Kontrol}

Pertama kali kita optimasi setting alat GCMS meliputi: suhu injektor dan detektor $200 \mathrm{C}$, suhu interface $300 \mathrm{C}$, suhu kolom $60-200 \mathrm{C}$ dengan kenaikan $10 \mathrm{C} /$ menit, tekanan $20 \mathrm{kPa}$, dan laju alir kolom $0,5 \mathrm{ml} / \mathrm{mnt}$. Setelah optimasi tercapai, kita injek sebanyak 0,1 mikroL sampel minyak sereh dapur dan direkam kadar sitralnya. Selanjutnya kita lakukan setiap seminggu sekali selama delapan minggu. Dari delapan minggu kita peroleh delapan data kadar sitral, dihitung rata-rata dan standard deviasi. Kemudian dibuat control chart. Garis tengah merupakan rata-rata \% citral yang diperoleh. Batas atas dan batas bawah garis kontrol adalah 3 kali nilai standar deviasi (SD). Apabila selama waktu pengujian (8 minggu) \% citral masuk dalam garis kontrol menunjukkan hasil uji minyak sereh dapur dengan metoda GCMS stabil.

\section{HASIL DAN PEMBAHASAN}

Minyak atsiri mengandung banyak senyawa volatil yang dapat diidentifikasi menggunakan alat Gas Chromatography (GC). Seperti penelitian sebelumnya aplikasi identifikasi minyak atsiri juga dapat menggunakan GCMS dengan verifikasi optimasi alat, aplikasi jenis minyak atsiri, dan jaminan mutu. Yang tidak kalah penting dari verifikasi ini adalah penentuan control chart untuk memastikan kestabilan metoda dari GCMS terhadap identifikasi minyak atsiri. Control chart dari penelitian ini mengambil salah satu jenis minyak atsiri, yaitu minyak sereh dapur. Minyak sereh dapur dipilih karena mudah didapatkan dipasaran dan murah. Dilakukan identifikasi minyak sereh dapur dengan menggunakan alat GCMS setiap 1 minggu sekali selama 8 minggu. Dari pembacaan atau identifikasi awal minyak sereh dapur menggunakan GCMS, didapatkan senyawa yang khas adalah citral dengan posisi isomer yang berbeda yaitu cis dan trans. Beda dengan minyak serai wangi yang hanya didapatkan senyawa khas citral tanpa ada bentuk isomernya. Jadi dalam kromatogram GCMS untuk minyak sereh dapur ada 2 peak yang dominan sesuai dengan Gambar 1 dan dijelaskan dengan nama senyawa sesuai dengan data MS di Gambar 2. 
Chromatogram Minyak sereh

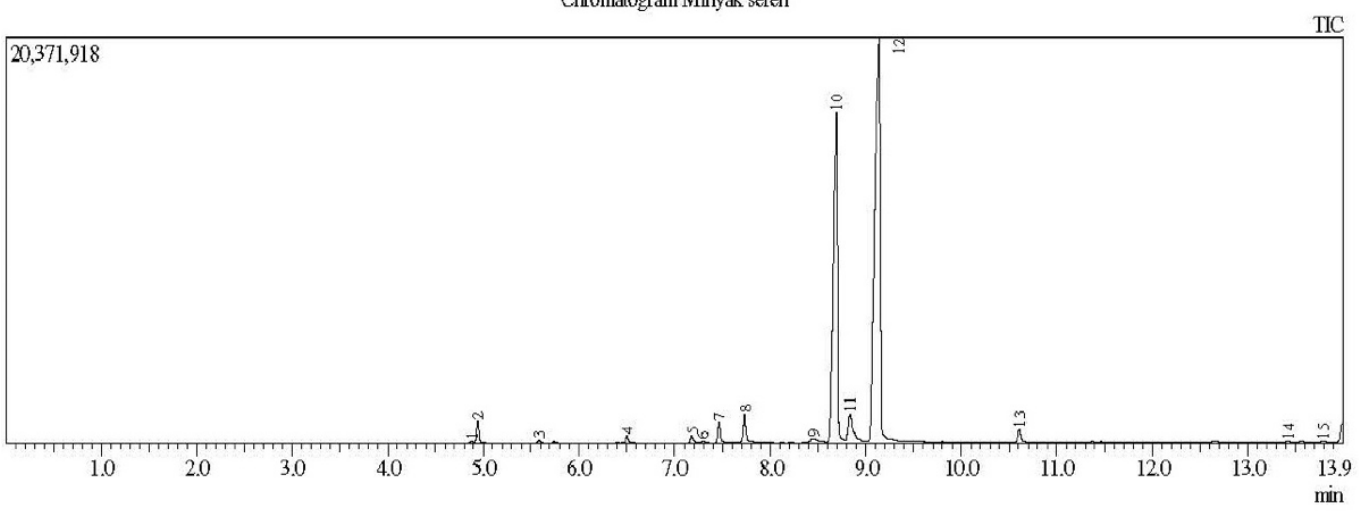

Gambar 1. Kromatogram minyak atsiri sereh dapur

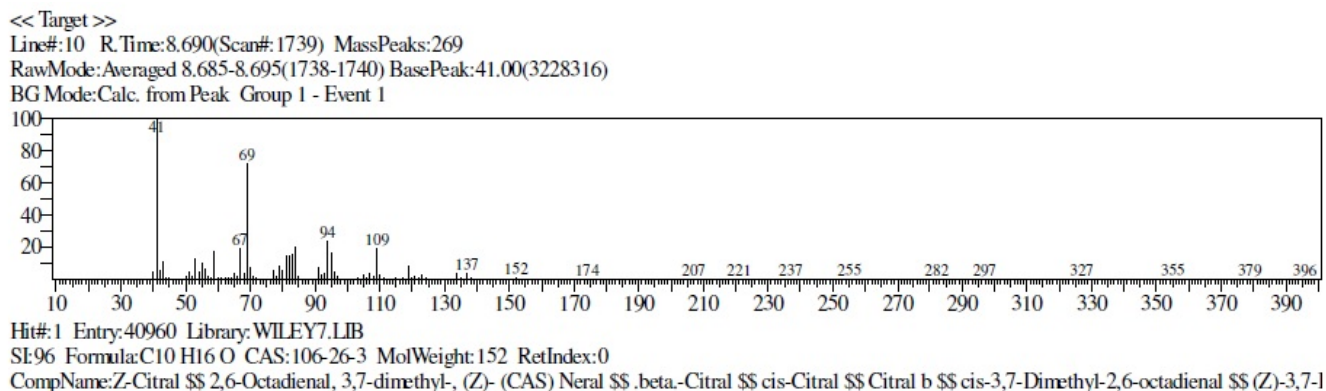

$\ll$ Target $>>$

Line\#:12 R.Time:9.140(Scan\#: 1829) MassPeaks:253

RawMode:Averaged 9.135-9. 145(1828-1830) BasePeak:41.00(4999917)

BG Mode:Calc. from Peak Group 1 - Event 1

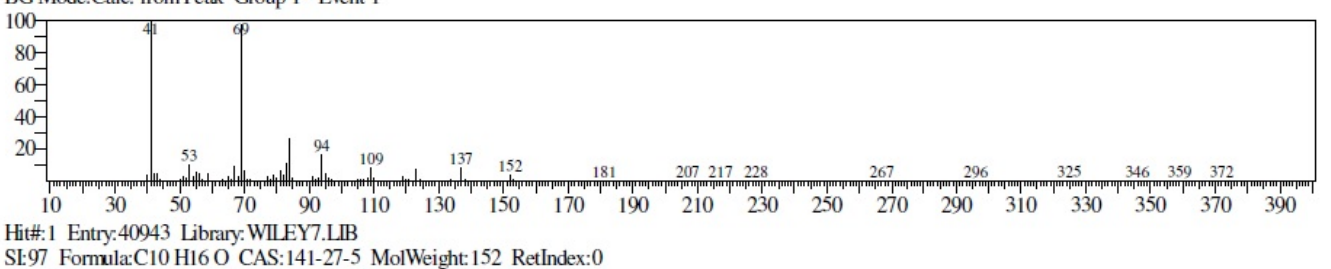

SI:97 Formula:C10 H16 O CAS:141-27-5 MolWeight:152 RetIndex:0

CompName:E-Citral \$\$ 2,6-Octadienal, 3,7-dimethyl-, (E)- (CAS) Geranial \$\$ trans-Citral \$\$Citral a \$\$Citral-a \$ (E)-Citral \$\$ Geranaldehyde \$\$ .alpha-Citr

Gambar 2. Data MS menunjukkan line/peak 10 adalah cis-sitral dan line/peak 12 adalah trans-sitral

Berdasarkan hasil identifikasi di atas menunjukkan bahwa minyak atsiri sereh dapur ada 2 senyawa citral, cis-sitral diperoleh pada waktu retensi 8,69 dan trans-sitral diperoleh pada waktu retensi 9,14. Ini berarti untuk penentuan control chart juga ada 2 data yang digunakan yaitu cis-sitral dan trans-sitral. Hasil yang diperoleh setelah 8 minggu pengukuran ditunjukkan pada Tabel 1 .

TABEL I. Hasil data control chart minyak sereh dapur, no 1 cis-sitral dan no 2 trans-sitral

\begin{tabular}{ccccccccc}
\hline No & \multicolumn{7}{c}{$\operatorname{Kadar}(\%) /$ minggu ke- } \\
\hline & 1 & 2 & 3 & 4 & 5 & 6 & 7 & 8 \\
\hline 1 & 33,82 & 36,11 & 36,21 & 31,35 & 34,52 & 34,44 & 32,36 & 36,08 \\
\hline 2 & 54,85 & 55,39 & 55,44 & 65,82 & 55,98 & 63,31 & 55,13 & 54,61 \\
\hline
\end{tabular}

Berdasarkan data pada No 1 yang tertera pada Tabel 1, maka langkah pertama mencari rata-rata kadar (\%) cis-sitral selama 8 minggu diperoleh nilai 34,36\%. Kemudian dicari nilai standar deviasi (SD) selama 8 minggu diperoleh nilai 1,8. Setelah itu dihitung batas atas control chart (UC) dengan menambahkan nilai rata-rata dengan 3 kali nilai SD diperoleh nilai 39,77. Batas bawah control chart (LC) dengan mengurangi nilai rata-rata dengan 3 kali nilai SD diperoleh nilai 28,94. Sehingga dapat 
dibuat control chart untuk cis-sitral seperti di Gambar 3.

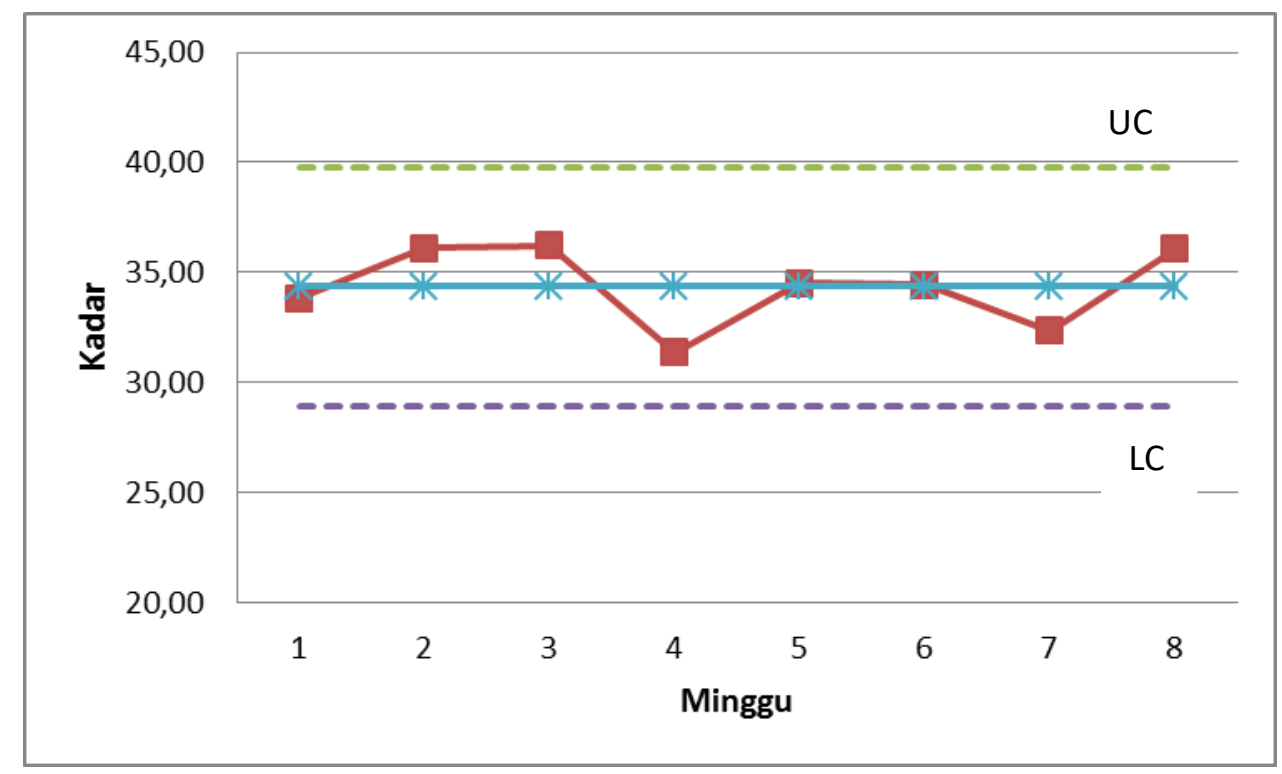

Gambar 3. Control chart senyawa cis-sitral minyak sereh dapur

Sedangkan dari data no 2, seperti langkah pertama mencari rata-rata kadar (\%) trans-sitral selama 8 minggu diperoleh nilai 57,56\%. Kemudian dicari nilai standar deviasi (SD) selama 8 minggu diperoleh nilai 4,39 Setelah itu dihitung batas atas control chart (UC) dengan menambahkan nilai rata-rata dengan 3 kali nilai SD diperoleh nilai 70,73. Batas bawah control chart (LC) dengan mengurangi nilai rata-rata dengan 3 kali nilai SD diperoleh nilai 44,39. Sehingga dapat dibuat control chart untuk trans-sitral seperti di Gambar 4. Hasil ini telah menunjukkan bahwa alat GCMS memiliki kestabilan yang baik dalam proses pengukuran dan identifikasi senyawa sitral dalam suatu bahan volatile organic compounds.

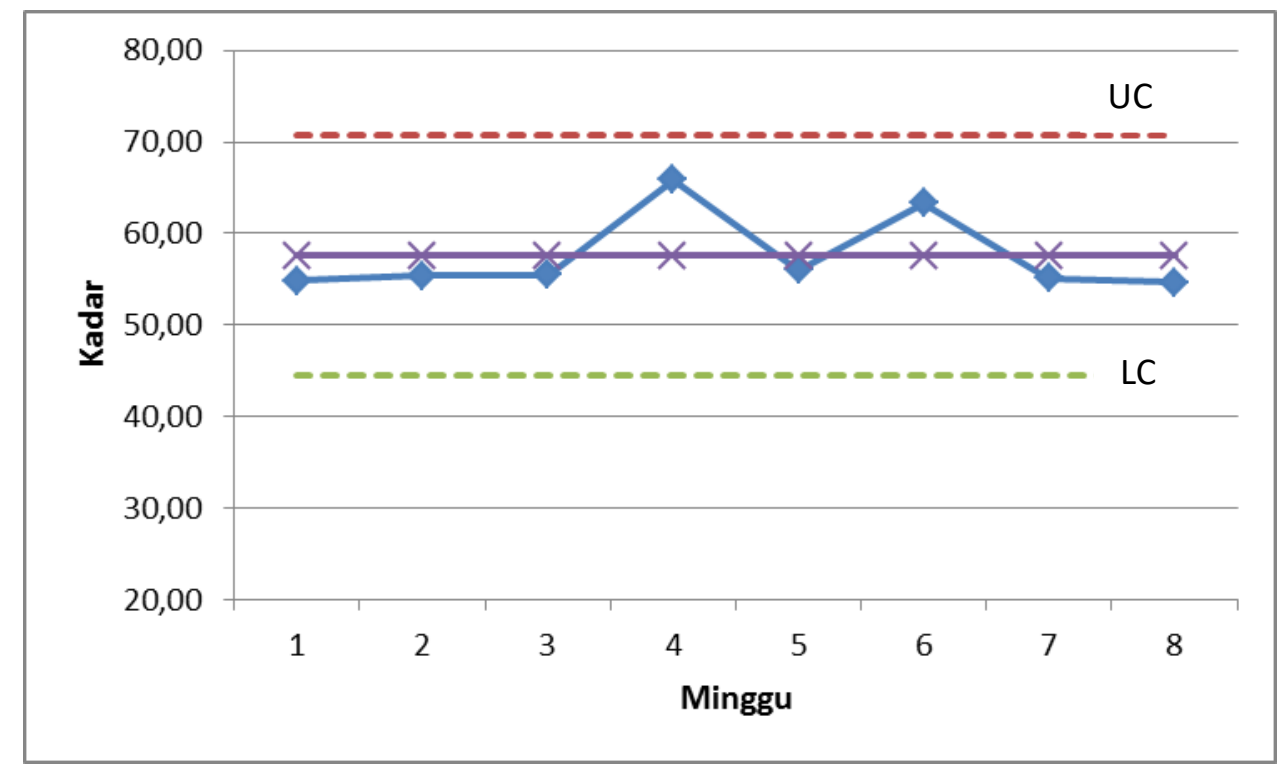

Gambar 4. Control chart senyawa trans-sitral minyak sereh dapur

\section{KESIMPULAN}

Berdasarkan gambar control chart untuk minyak atsiri sereh dapur, baik senyawa cis-sitral maupun trans-sitral, nilai rata-rata kadar dalam persen berada dalam rentang atas (UC) dan rentang 
bawah (LC) menunjukkan metoda yang digunakan stabil. Jadi metoda GCMS yang diaplikasikan untuk minyak atsiri merujuk dari penelitian sebelumnya yaitu optimasi, dan jaminan mutu diperkuat dengan hasil control chart yang stabil untuk rentang waktu 8 minggu yang penulis lakukan.

\section{Daftar Pustaka}

[1] Sofiah, S., "Cymbopogon Citratus Sebagai Salah Satu Tanaman Penghasil Minyak Atsiri”, UPT Balai Konservasi Tumbuhan Kebun Raya Purwodadi-LIPI, Jl. Raya Surabaya-Malang Km. 65, PasuruanJawa Timur, 2008.

[2] Wilis, A.O., Marsaoly R.H., Ma'sum, Z., “Analisa Komposisi Kimia Minyak Atsiri Dari Tanaman Sereh Dapur dengan Proses Destilasi Uap Air”, eUREKA: Jurnal Teknik Kimia, Universitas Tribhuwana Tunggadewi, 2017.

[3] Slamet, Supranto, Riyanto, "Studi Perbandingan Perlakuan Bahan Baku Dan Metode Distilasi Terhadap Rendemen Dan Kualitas Minyak Atsiri Sereh Dapur (Cymbopogon citratus)", ASEAN Journal of Systems Engineering, Vol. 1, No.1, 25-31, 2012.

[4] Habibi. Y., "Pengaruh Variasi Optimasi Alat GCMS Terhadap Kadar 1,8-cineol pada Minyak Kayu Putih", Penelitian Laboran, DPPM UII, 2014.

[5] Habibi. Y., "Aplikasi Optimasi Alat GCMS Terhadap Kadar Senyawa Khas pada Berbagai Minyak Atsiri”, Penelitian Laboran, DPPM UII, 2015.

[6] Habibi. Y., "Relative Percent Difference (RDP) Sebagai Jaminan Mutu Optimasi Alat GCMS Aplikasi Senyawa Khas pada Berbagai Minyak Atsiri”, Proseeding Seminar Nasional SAINTEK, Universitas Wahid Hasyim, 2019.

[7] Shah, S., Shridhar, P., Gohil, D., "Control Chart: a statistical process control tool in pharmacy", Asian Journal of Pharmaceutics: July-September, 2010.

[8] Kesumawati, A., Mashuri, M., Irhamah, "Fuzzy T2 Hotelling Control ChartFuzzy T2 Hotelling Control Chart", Jurnal EKSAKTA, Vol 14, 41-51, 2014.

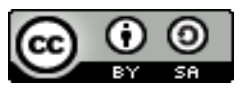

Jurnal IJCA is licensed under aÂ Creative Commons Attribution ShareAlike 4.0 